\title{
M - Commerce Payment methods, Services and Application: An Overview
}

\author{
Abhijeet R. Patil \\ Lecturer, Bharatesh College of Computer Applications, Belagavi, Karnataka, India
}

\begin{abstract}
M - Commerce or Mobile commerce has come a long way breaking the traditional barriers and limitations. Commerce that we knew is buying and selling of goods or products. With the expansion and the growth in the electronics technology and the birth of internet, gave new dimensions to the traditional commerce, which we call it as E-Commerce or electronic commerce where we sell and by products on the internet. Now it has further expanded its boundaries to new age commerce that is $\mathbf{M}$ - Commerce. $\mathbf{M}$ - Commerceor mobile commerce is selling and buying products online (internet) using wireless electronic devices such as mobile phones. Now day's mobile phones have become part and parcel of our life. The days are gone were mobile phones were used only for making calls on the move, but now using the mobile phones we can carry out many task of our day-to-day activities i.e. Any transactions we want to carry out such as payment of bills i.e. telephone, electricity or any money transfer between banks or online shopping, it can be done with ease and conveniently using our mobile phone. Now there are varieties of mobile applications that have been developed, to assist the mobile phone users to carry out the transactions securely. The purpose of this paper is to explore and provide an overview of the variety of services and applications available under mobile commerce or $\mathrm{M}$ - Commerce.
\end{abstract}

Keywords: Mobile -Commerce, Mobile - Commerce services, Mobile - Commerce Applications, Mobile - Commerce mode of Payments.

\section{INTRODUCTION}

Mobile commerce or $\mathrm{M}$-Commerce has given the user the capabilities to carry out any financial or non financial transactions easily and efficiently, anywhere, via wireless technology. The development of mobile applications and services for internet enabled mobile phones has given a new meaning to the term commerce. It has taken the traditional commerce to a new level and within the reach of the common user. We can buy food from the restaurant, by using applications on mobile and also make payments easily. We can get access to books online through the applications on mobile phone by paying nominal fees. We can watch cinema, download music, and carry out financial transactions. This paper explores the various applications and services that are available to aid the user to carry out various forms of activities of purchasing, payments, browsing which are regularly performed on internet based smart phone or mobile devices. The mobile applications developed these days are robust and more secure. The mobile services and applications are design and developed following the strict rules and regulations of the internet world. These mobile applications give the users the comfort and ease of usability, at the same time securing their identity. The mobile phones are now days called as "Smart Phones" because the phones are not smarter it is due to the applications and services that are developed for mobile phones have become smarter.

\section{II. $\quad$ NEED AND SCOPE OF $\mathrm{M}$ - COMMERCE}

The uses of mobile phones have increased tremendously and have penetrated into each and every life of the human beings whether it is elderly people, college or school going children. This has happened due to drastic fall in the prices of smart phones and very user friendly to use. The mobile phones are not only used for sending messages, butnow with internet facility in the mobile phone, usability has extended for online transactions like sending emails, online bank transactions, paying bills, online shopping, booking tickets online. The use of more online transactions by the user, has led to the development of online based applications and services. These mobile applications and services have helped both the user and the service oriented institutions like banks, online shopping portals, and financial portals to use their facilities very easily and efficiently. In recent times researchers have seen there has been rapid growth in the use of online shopping and online money transfer.The 
banking sectors, service providers, financial firms, mobile operators and government agencies are coming closer and supporting each other to take $\mathrm{M}$ - Commerce to a new level.

\section{CHARACTERISTICS OF M - COMMERCE}

- $\quad$ Mobility

The mobile users can get connected to any device or system even when the users are moving from one location to another.

- Broader reach

The people using mobile phone can get connected to each other at any movement of time and share information.

- Ubiquity

Mobile users can get connected to other user irrespective of the geographical location at any moment of time.

- $\quad$ Convenience

It becomes easy for the users to communicate and share information wirelessly, all they need is a smart phones and internet facility.

- Instant connectivity

Mobile phone can get connected to the any networks like internet, intranet, Wi-Fi, NFC enabled facility, easily and efficiently.

- $\quad$ Localization of products and services.

The services can be provided to the customers on the go, by locating their physical locations.

- Personalization

Information can be made available as per the requirements of the customers.

\section{OBJECTIVE OF M - COMMERCE}

To find the characteristics and features of $\mathrm{M}-$ Commerce.

$>\quad$ To understand the services of $\mathrm{M}$ - Commerce.

$>\quad$ To find the various applications available in $\mathrm{M}$ - Commerce.

$>\quad$ To find the mode of payments in $\mathrm{M}$ - Commerce.

$>\quad$ To understand how $\mathrm{M}$ - Commerce have evolved to carry out transactions on internet.

\section{MOBILE COMMERCE SERVICES AND APPLICATIONS}

\section{- $\quad$ Mobile Browsing}

The browser present in the mobile phones allows the user to access any shopping portal and do online purchases without actually being physically present at that location. It also gives the user the convenience to be free from their personal computers for such on - line activities. E.g. UC browser, Opera mini etc.

\section{- $\quad$ Auctions}

Mobile auctions are more interactive than traditional auctions. The user can bid on auction items using their own mobile phones. Mobile auctions provide a better platform for the user to raise money as it is very easy to use and with increased competitions between users, it makes the user to bid more to raise money. E.g. Forward Auction, Vickrey Auction, Reverse Auction.

- $\quad$ Content Purchase and delivery 
It is mainly selling of pictures, ring-tones and mobile games for smart phones. The combination of audio and video in one device is gaining popularity among the mobile users. If the speed of mobile network is fast then the audio and video content can be downloaded within few seconds. E.g. Zapak Digital Ltd, Kreeda Games etc.

\section{- $\quad$ Mobile money transfer}

Mobile ATMs are self-efficient units that do not require a building or kept in enclosures. The mobile ATM can be placed at any location and can transmit transaction information wirelessly. The mobile service providers are working to provide efficient way to implement this service and proper distribution of the network for convenient flow of cash transactions. E.g. Safaricom, Airtel etc.

- $\quad$ Mobile vouchers, coupons and loyalty cards

The distribution of vouchers, coupons, and loyalty cards can be done using mobile technology. Thevouchers, coupons, and loyalty cardsare represented by a virtual token that is sent to the mobile phone. A customer presenting a mobile phone with one of these tokens at the point of sale receives the same benefits as if they have the traditional token. Stores may send coupons to customers using location-based services to determine, when the customer is nearby. E.g. American Express, Apple Pay etc.

\section{- $\quad$ Location-based services}

The Location based services can be used in health, vehicle tracking, personal life etc. The mobile phone user's location is an important piece of information used during mobile commerce or m-commerce transactions. Knowing the location of the user allows for location-based services such as:

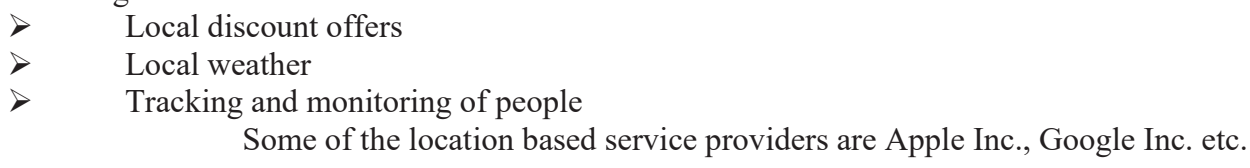

\section{- Information services}

Now day's variety of news or information services can be delivered to the mobile phone users. These services include:

$\begin{array}{ll}> & \text { News } \\ > & \text { Stock quotes } \\ > & \text { Sports scores } \\ > & \text { Financial records } \\ > & \text { Traffic reporting } \\ & \text { Emergency Alerts }\end{array}$

- $\quad$ Mobile Ticketing

Now day's tickets can be sent to mobile phones. Here users receive their tickets on their mobile phone. These digital tickets can be used immediately, by presenting their mobile phone at the ticket check as a digital boarding pass. Most of the users are now using this technology. E.g. IRCTC, Mobifin, etc.

\section{- $\quad$ Mobile Banking}

Customers can get access to the account information from Banks or financial transactions form financial institutions such as money transfers or purchasing of stocks. Such financial transaction is called as mobile banking or m-banking. Mobile banking services include:

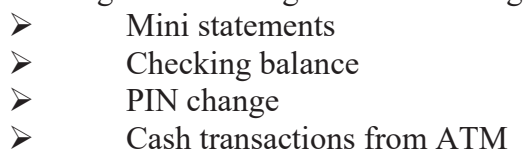

\section{- $\quad$ Mobile brokerage}

The facility of stock market given on smart phones using applications to carry out trading activities is known as Mobile brokerage. The user can participate in the stock market activities and carry out the transactions immediately without being actually present physically at the stock market location.

\section{- $\quad$ Mobile purchase}

Mobile users can buy products from wireless application protocol supporting mobile websites by clicking on the website link, and making the payments for the products by sending the SMS. Value-add up services and offers 
are sent to customers who make frequent purchases on mobile.There are websites developed by the merchants that are designed for the smaller screen and limited user interface of a mobile device.

- $\quad$ Mobile marketing and advertising

From mobile commerce perspective mobile marketing is marketing sent to mobile phones. Now advertising on mobile phones is far more responsive than traditional way of doing advertisement. The different types of mobile marketing and advertising are:

$>\quad$ Mobile web poster

$>\quad$ Mobile games

$>\quad$ Mobile videos

$>\quad$ Short Messaging Service Advertising

$>\quad$ Multimedia Messaging Service Advertising

\section{PAYMENT METHODS USED IN MOBILE COMMERCE}

\section{- $\quad$ Premium-rate telephone numbers}

Premium-rate telephone numbers are telephone numbers for telephone calls during which certain services are provided, and for which prices higher than normal are charged. Unlike a normal call, part of the call charge is paid to the service provider, thus enabling businesses to be funded via the calls. E.g. Directory enquiries, weather forecast, etc.

\section{- $\quad$ Contactless payment}

Contactless payment systems are credit cards and debit cards, key fobs, smart cards or other devices, including smart phones and other mobile devices, that use radio-frequency identification (RFID) or near field communication (NFC) for making secure payments. E.g. Apple Pay, Android Pay. Etc.

\section{- Host Card Emulation}

Host Card Emulation (HCE) is the term describing on-device technology that permits a phone to perform card emulation on a Near Field Communication (NFC)-enabled device without relying on access to a secure element. E.g. Google Wallet

\section{CONCLUSION}

$\mathrm{M}$ - Commerce is now the call of time and is reaching the every corner of the world, as the mobile phones have reached to every geographical locations of this world. $\mathrm{M}$ - Commerce is very useful for both the companies and mobile users, as it is more convenient, economical and easy to use. People are now finding $\mathrm{M}-$ Commerce a new and innovating means of carrying out transactions, as it can be done from anytime and anywhere. This paper gave the insight of the $\mathrm{M}$ - Commerce world and how it has evolved with the technology. The $\mathrm{M}$ - Commerce has given the user a new approach of carry out the business transaction.

\section{REFERENCES}

[1] https://en.wikipedia.org/wiki/Mobile_commerce.

[2] Dr. Pravin H. Bhatawal, Anshu Agarwal International Journal of Research in Computer and Communication Technology, Vol.4 (4), April - 2015 .

[3] Sachdeva, Sahil. "Mobile Commerce: An Overview" Seminar Mobile Services, Technische Universitaet Berlin Version vom July 11, 2010, pp. $1-9$

[4] Turban, Leidner, McLean, Wetherbe , Information Technology For Management 6th Edition, Modified from Lecture Slides by L. Beaubien, Providence College, John Wiley \& Sons, Inc. pp.1 - 34.

[5] Manoj Giri et al, (IJCSIT) International Journal of Computer Science and Information Technologies, 2014 , Vol. 5 (4).pp.1 - 3.

[6] Mandaliya, Pravinchandra Mitesh (IJIET) International Journal of Innovations in Engineering and Technology, 2014, Vol.4 (4), pp.346-349.

[7] Agarwal, Anshu, Bhatawal, H Pravin International Journal of Research in Computer and Communication Technology, 2015, Vol.4 (4). pp. $273-276$. 